Fanum

Sociológico

\section{Forum Sociológico}

Série II

33 | 2018

Número 33

\title{
Uma hipertrofia do presente : Do trabalho e das situações de trabalho numa organização start-up
}

A hypertrophied sense of the present: Work(ing) in a start-up organization

João Vasco Coelho

\section{(2) OpenEdition}

Journals

Edição electrónica

URL: https://journals.openedition.org/sociologico/2502

DOI: $10.4000 /$ sociologico. 2502

ISSN: 2182-7427

Editora

CICS.NOVA - Centro Interdisciplinar de Ciências Sociais da Universidade Nova de Lisboa

\section{Edição impressa}

Paginação: 47-54

ISSN: 0872-8380

Refêrencia eletrónica

João Vasco Coelho, «Uma hipertrofia do presente : Do trabalho e das situações de trabalho numa organização start-up», Forum Sociológico [Online], 33 | 2018, posto online no dia 30 dezembro 2018 , consultado o 31 março 2022. URL: http://journals.openedition.org/sociologico/2502 ; DOI: https:// doi.org/10.4000/sociologico.2502 


\title{
UMA HIPERTROFIA DO PRESENTE: DO TRABALHO E DAS SITUAÇÕES DE TRABALHO NUMA ORGANIZAÇÃO START-UP
}

\section{A HYPERTROPHIED SENSE OF THE PRESENT: WORK(ING) IN A START-UP ORGANIZATION}

\author{
João Vasco Coelho \\ Centro de Investigação e Estudos em Sociologia (CIES-IUL), Instituto Universitário de Lisboa (ISCTE-IUL), Portugal
}

\begin{abstract}
Resumo
O universo start-up tem vindo a ser apresentado, em termos públicos, mediáticos e políticos, como uma possível nova via para o crescimento económico português. A referência a uma organização start-up, define, no presente, uma amenidade, uma platitude, correlativa do louvor dos seus méritos como factos consumados. Perspectivas alternativas deste fenómeno são pouco frequentes ou pouco visíveis. O presente artigo equaciona as implicações da natureza temporária de uma organização start-up, apresentando os resultados de uma pesquisa longitudinal concretizada num contexto organizacional específico. Partindo da análise apresentada, sugere-se que as situações concretas de trabalho numa organização start-up são potencialmente enformadas por atributos socioculturais particulares, decorrentes de uma conceção e de um uso particular do tempo: a impermanência normativa, o foco concedido à ação, a secundarização do conflito, o fervor finito da experiência vivida.
\end{abstract}

Palavras-chave: start-up, inovação, empresas e organizações, organização temporária

\begin{abstract}
In recent years, Portugal has been increasingly presented as a "start-up nation". In this context, critical perspectives are rather scarce (or visible). This paper aims to go beyond dominant discourses of (public, political and mediatic) glorification, by conceiving a start-up as an temporary organization, an analytical lens used to uncover some of its less visible dimensions. Analytical work is anchored in qualitative interview and direct observation data, gathered during a 12 months longitudinal research, held in one of the most successful start-ups created in Portugal, in the last three years. A hypertrophied sense of the present, a sense of normative impermanence, actiondriven practices and short-termed social relations are suggested to be attributes that contribute to define management practices and individual work experience(s) in start-up organizations.
\end{abstract}

Keywords: start-up, innovation, companies and organizations, temporary organizations

\section{Introdução: Uma celebração como ponto de partida}

A elevada taxa de insucesso observável no desempenho de uma organização start-up é uma constatação empírica recorrente (Aldrich \& Martinez, 2001; Hanage, Scott \& Davies, 2015; Krauss, 2009; Singh, Corner \& Pavlovich, 2015; Ucbasaran, Shepherd, Lockett \& Lyon, 2013). Não obstante este dado empírico, o fracasso, o desaparecimento de uma organização start-up, recolhe escassa atenção pública (Krauss, 2009), se comparado com as histórias de sucesso frequentemente mediatizadas, gerando uma imagem truncada deste fenómeno enquanto realidade social e económica.

O universo start-up tem vindo a ser apresentado, em termos públicos e políticos, como uma oportunidade de "Portugal vir a ser um outro país", apresentando-se, no panorama internacional, não como a "(...) Florida da Europa, mas como o Silicon Valley da União" (Santos, 2016). Não obstante a posição periférica que tende a caracterizar (e a apresentar) Portugal (CB Insights, 2016) no quadro europeu, diferentes fatores têm vindo a contribuir 
para que o país, em proporção com a dimensão da sua economia e valor do PIB nacional, se afirme como uma referência no contexto europeu de start-ups (Butcher, 2017; Robinson, 2017), um modelo a seguir, uma "nação start-up" (Oliveira, 2016). O (baixo) custo de vida, a qualidade de vida, os (baixos) custos do trabalho, a qualificação dos trabalhadores (em particular, no domínio das engenharias e das tecnologias de comunicação e informação), a abertura intercultural, a segurança, a estabilidade institucional, são fatores tipicamente valorizados (celebrados), ao nível das práticas discursivas institucionais, como facilitadores da angariação de investimento estrangeiro e da localização de organizações start-up e de profissionais em território nacional (Medeiros, 2016).

Interrogando uma celebração: Uma hipótese de trabalho

Atendendo à evidência empírica existente e tendo em conta a atenção e o investimento público que a recente eclosão do fenómeno start-up tem suscitado em Portugal, considera-se relevante procurar compreender esta realidade socioeconómica nas suas diferentes dimensões constitutivas, complementando as perspectivas macro e meso prevalecentes nos estudos que têm vindo a ser realizados em Portugal acerca das organizações start-up, centrados na análise do impacto das agendas de política pública e da estratégia industrial de agentes privados, e no papel de diferentes agentes económicos na configuração de clusters locais, regionais, nacionais e internacionais de fomento de inovação (Baptista \& Preto, 2011; Rocha, Simões, Mello \& Carneiro, 2017; Urze \& Abreu, 2015).

Retomando o estudo realizado por Hwang e Horowitt (2012), onde se sugere que especificidades organizacionais apensas à situação concreta de emprego e de trabalho dos indivíduos constituem fatores debilitantes do desempenho de uma organização start-up, um dado empírico é adotado como eixo de problematização no presente artigo: o elevado grau de incerteza da continuidade de existência de uma organização start-up. Adota-se, neste sentido, a título de hipótese de trabalho, a possibilidade de uma organização start-up constituir um contexto social de produção de situações de trabalho particulares, uma organização de natureza temporária (Lundin \& Soderholm, 1995) produtora de especificidades normativas no quadro socioeconómico português, procedentes da constituição de racionalidades organizacionais particulares, matizadas pelos efeitos de uma temporalidade finita.

\section{Uma organização temporária}

Para autores como Blank (2010), uma organização start-up designa uma forma de organização de natureza temporária (Bakker, 2010; Lundin \& Soderholm, 1995), cujo foco central de atuação é dado pela procura de um modelo ou objeto de negócio inovador, repetível, escalável. Uma formulação próxima é sugerida por Ries (2016, p. 23): "O objectivo de uma start-up é encontrar a coisa certa para construir - o que os clientes querem e pagam para ter - o mais rapidamente possível, em condições de incerteza extrema". Perspectivar uma organização start-up como forma organizacional de natureza contingente e temporária define, neste sentido, um modo de ver que permite ir ao encontro de especificidades sociais e organizacionais distinguíveis numa organização start-up.

Bakker (2010, pp. 468-469) procura precisar o sentido da natureza temporária das formas temporárias de organização, referindo que aquela decorre da existência de um período pré-definido (ex ante) de tempo, que baliza, limitando (no tempo), as relações sociais estabelecidas no seio da organização. Para o autor, importa considerar, porém, que as novas formas de organização da ação socioeconómica são fundamentalmente temporárias, constituindo o tempo e o temporário importantes conceitos sensibilizadores na análise das estruturas e das formas sociais e institucionais que caracterizam a organização do trabalho contemporâneo.

Para Saunders e Ahuja (2006) é possível identificar especificidades nas relações e nos processos sociais que são estabelecidos no seio de uma organização temporária, em particular no referente a dois eixos particulares: 1) a relação que os indivíduos estabelecem com as práticas de gestão, as tarefas e as atividades de trabalho; e 2) a relação estabelecida entre pares e elementos das equipas de trabalho.

No referente à relação com os modos de gestão e às condições de realização das atividades de trabalho, importa considerar a evidência empírica que indica que a exploração intensiva e o erro tendem a enquadrar a praxis observável no contexto de uma organização start-up, em particular nas etapas iniciais (early stage) da sua existência (Ries, 2016). Trata-se de uma lógica organizacional e de uma cultura de gestão que visa a inovação radical (Mclaughlin, Bessant \& Smart, 2005), assente em estruturas organizacionais orientadas para a angariação de conhecimento, a experimentação, a tolerância ao risco e o questionamento persistente.

No concernente às relações estabelecidas entre pares, observa-se que num grupo ou organização onde se antecipa a existência de uma duração temporal limitada para as relações estabelecidas ou a estabelecer, se verifica que o foco da ação e das práticas sociais é colocado no presente imediato (Eriksen, 2001). O tempo perspectivado como disponível para a redução de distâncias sociais e cognitivas é mínimo ou inexistente, o que instila a 
reificação e a inculcação de um sentido particular de urgência no espaço social de trabalho.

\section{Metodologia}

O presente artigo tem por base um estudo de natureza longitudinal, com duração de 12 meses, consumado no decurso do ano de 2015 numa das organizações start-up portuguesas que apresentou maior crescimento e visibilidade nos últimos três anos (Medeiros, 2016). Na sua orientação teórico-metodológica, a pesquisa assumiu a configuração de uma análise intensiva de um campo de observação restrito, concretizada pela consideração de um caso particular (Flyvberg, 2006) para efeito de observação empírica. Trata-se de uma estratégia de aproximação (analítica) a uma realidade social que se afigurou ajustada à procura de compreensão de um contexto organizacional específico, ainda pouco explorado ou de consideração emergente.

$\mathrm{Na}$ identificação do caso considerado em termos empíricos, procurou-se a consistência com o objectivo cognitivo geral subjacente ao plano de pesquisa: desafiar o efeito de evidência associado a uma realidade social e organizacional particular, objeto de celebração e de normalização, em termos públicos, mediáticos e políticos. Nesta identificação, visou-se a autenticidade, isto é, a possibilidade do caso considerado representar uma situação total, uma totalidade expressiva, em relação à problemática em estudo (Ragin \& Amoroso, 2011). Tratando-se de uma realidade emergente no contexto socioeconómico português, caracterizada, à data de início da pesquisa empírica, pela prevalência de organizações em estado nascente (early stage), centradas no desenvolvimento de produtos ou soluções de base tecnológica (Start-up Europe Partnership, 2015), o objetivo referido foi concretizado pela identificação de uma organização start-up de origem portuguesa, de base tecnológica, que se encontrava, à data, numa fase nascente (early stage) de desenvolvimento organizacional (3 anos de existência; 2 rondas de investimento já concretizadas).

Dada a natureza do campo considerado como referente empírico, considerou-se adequado, em termos de estratégia geral de investigação, a articulação de diferentes técnicas ou vias de compreensão analítica. No caso vertente, as técnicas acionadas foram a observação direta, a entrevista e a análise de fontes estatísticas secundárias (CB Insights, 2016; Start-up Europe Partnership, 2015; Startup Genome, 2017) e documentais (fontes web e peças de divulgação jornalística) (Blank, 2010; Butcher, 2017; Graham, 2012; Kriss, 2016; Oliveira, 2016; Ramos, 2017; Robinson, 2017; Santos, 2016).

Com o uso da observação direta, visou-se uma aproximação à experiência vivida de uma realidade social específica, procurando trazer o espaço teórico de uma inquirição de orientação sociológica a dimensões tácitas associadas à experiência concreta de temporalidades e de contingências específicas. Foi adotada (e permitida), neste sentido, uma estratégia imersiva que exigiu a intervenção explícita e a assunção quotidiana de um papel formal por parte do investigador ("líder da área de recursos humanos"), no decurso do período de observação.

Com as entrevistas visou-se, no essencial, a recolha de dados relativos à perceção dos atores sobre aspetos particulares associados às práticas de organização e prestação de trabalho. Três tópicos orientaram as entrevistas realizadas: i) orientação estratégica, estruturas de coordenação e organização; ii) práticas de gestão do trabalho e dos recursos humanos em uso; iii) relações estabelecidas com a organização e com as práticas em uso. No total, foram realizadas seis entrevistas semiestruturadas: duas a gestores, quatro a trabalhadores da organização start-up objeto de análise. No que concerne às fontes estatísticas e documentais utilizadas, o seu uso visou localizar a realidade em estudo em termos macro.

Os registos de autorreflexão (Cunliffe \& Karunanayake, 2013) procedentes da observação direta e a informação recolhida em contexto de entrevista permitiram a constituição de um diário de campo (Czarniawska, 2007). Os materiais empíricos nele reunidos foram objeto de categorização temática com o apoio de software específico (MaxQDA v.12). Tratando de uma pesquisa centrada na análise de um contexto organizacional particular, com base em materiais empíricos de índole qualitativa, procurou-se assegurar o controlo da fiabilidade da análise, introduzindo um nível de reflexividade metodológica (Johnson \& Duberley, 2003) através da revisão de produtos analíticos intermédios com pares, da sua discussão em conferências, e do escrutínio procedente da submissão de propostas de artigos a revistas científicas.

Duas direções de interpretação dos materiais empíricos recolhidos foram identificadas, inspiradas em parte pelo modelo analítico proposto por Saunders e Ahuja (2006), anteriormente mencionado: 1) a relação que os indivíduos estabelecem com a organização (estratégia, práticas de gestão, tarefas e atividades de trabalho); e 2) a relação estabelecida na organização (relações estabelecidas pelos indivíduos com gestores, pares, parceiros externos, equipas de trabalho). Decorrendo destes eixos foram redigidas duas narrativas (Cole, 2013; Czarniawska, 1997), ilustrações empíricas que se apresentam no ponto seguinte. Considera-se que as narrativas apresentadas reportam em si mesmo, como veículos de conhecimento e de comunicação de conhecimento, um reflexo representativo das tendências-chave do fenómeno social em análise - 
a prestação de trabalho e as situações de trabalho numa organização start-up.

\section{Duas narrativas, resultado de uma observação empírica}

A ideia motriz da organização start-up tomada como caso concreto pela pesquisa, surgiu de uma dificuldade sentida pelos seus fundadores em identificar alternativas de alojamento em Portugal, após percursos escolares compostos em diferentes pontos do globo. A sua intenção passava por criar um negócio em conjunto, algures na Europa. A dificuldade em encontrar alojamento para si próprios aproximou-os de um mercado ainda por explorar: as soluções de alojamento de longa duração vocacionado para estudantes universitários.

No decurso do período considerado para efeito de observação empírica (ano de 2015), a organização start-up considerada triplicou, em termos líquidos, a dimensão da sua equipa (de 40 para 120 trabalhadores), lançou duas versões do seu produto (uma plataforma eletrónica), ampliou o seu escritório-sede em Portugal. Os seus provei- tos operacionais quadruplicaram, a sua presença internacional quintuplicou, assim como o número de utilizadores ativos da solução disponibilizada, multiplicadores, ainda assim, abaixo dos objetivos traçados como desejáveis para o período em questão. Neste período, a taxa de rotatividade (turnover) de recursos humanos manteve-se sempre acima de dois dígitos, um dado que é afirmado como recorrente em organizações start-up (Ries, 2016).

Resultando do trabalho de análise efetuado, apresentam-se de seguida duas narrativas, cuja composição visa ilustrar, a título de suporte empírico, duas dimensões particulares da organização do trabalho, da experiência do trabalho e das situações de trabalho observáveis na organização start-up objeto de análise: 1 ) a relação que os indivíduos estabelecem com a organização (Quadro 1. Narrativa \#1: "Getting sh!t done."); e 2) a relação estabelecida na organização (Quadro 2. Narrativa \#2: "Let's move on, please."). Estes suportes narrativos são objeto de discussão no ponto seguinte, utilizando-se excertos dos mesmos como via de elucidação empírica do argumento que é apresentado a cada momento.

Quadro $1 \triangleright$ Narrativa \#1: "Getting sh!t done."

A 10 de Novembro de 2014 teve início o período de observação e de intervenção quotidiana na organização. Assumi, nos primeiros dias, pelo discurso exaltante, pela acutilância da maioria das questões apresentadas, pela impressão de sofisticação sentida, que estava perante um contexto onde existia experiência de gestão, práticas relativamente estáveis, objetivos definidos, uma visão de futuro. Percebi-o, pouco tempo depois de iniciada a observação: a experimentação, em particular, no domínio da gestão, era incessante, era um modus vivendi apenso à própria natureza organizacional daquela start-up, das organizações start-up numa fase early stage, pelo que me foi referido. As práticas mudavam numa base semanal, diária, no mesmo dia, se necessário, se assim fosse por alguém decidido. A definição de atividade, de projeto, de sucesso, era fundamentalmente contingencial, situada, mutável.

A minha primeira tarefa passou pela criação e apresentação de um orçamento para a área de recursos humanos, em dois dias, que enquadrasse o crescimento esperado para o ano de 2015. Desconhecia a organização, as suas práticas, o seu histórico. Percebi, pouco tempo depois, que o histórico era irrelevante, assim como a História, o sentido histórico, em termos gerais. O dito orçamento era, no presente, menos um instrumento de regulação e controlo interno, e mais um instrumento de gestão de impressões junto de investidores, relevante na caução da legitimidade das operações e das decisões a tomar internamente. Uma proposta de orçamento foi entregue no dia seguinte. Foi discutido durante dez minutos com dois dos fundadores, no canto de uma mesa. Foi ali, assim, aprovado. O seu envio (aos investidores) foi celebrado de forma efusiva (pelos fundadores).

No dia-a-dia, muitos apresentam-se como gestores de alguma coisa, cabeças ("Head of") de uma área. Categorias, títulos, muitas vezes, inexistentes em termos formais, e dissonantes com as realizações e as responsabilidades definidas. Muitos indicam merecer um aumento salarial. São muitas horas passadas a fazer coisas ("I'm getting sh!t done" - ouve-se frequentemente). As pessoas faziam, de facto, coisas. Tentavam, aprendiam, experimentavam, experimentavam-se. As coisas a fazer, as próprias atividades de trabalho não estavam definidas, por não estar definido o que era o objetivo comum da empresa, de cada área, de cada pessoa, em função de um papel atribuído.

O "sonho": "It's important to sell them the dream", enfatiza um fundador, acerca das práticas em vigor: de recrutamento, de gestão da satisfação individual, de acompanhamento da equipa. O "sonho" omite, por definição, a incerteza, a destituição do ser em favor do acontecimento. O que a start-up é ou faz, é no essencial incerto, flutuante, efémero. Não interessa tanto definir aquilo que se "é", aquilo que a start-up "é", aquilo que cada área ou função "é", o que é preciso é que haja coisas que aconteçam. A start-up faz, logo existe. A eficácia e o desperdício são secundarizados, definindo uma invisibilidade em termos de decisão, de prioridade, de discurso, subordinados à necessidade de fazer, de crescer. 
Não há tempo para pensar. Age-se. Os processos de decisão são, muitas vezes, marcados pela intempestividade, por um quórum parcial, a participação rarefeita. Em várias ocasiões, a decisão é apresentada como tendo sido já tomada e comunicada pelo "responsável". Um despedimento, a expansão internacional para uma nova cidade, uma ideia que um fundador teve ("Vamos para a China"), uma decisão de recrutamento que um fundador tomou na véspera. Por cada decisão tomada deste modo, há um distanciamento, um sentido de indiferença que é incitado em surdina.

Fonte: Extratos de diário de campo (Elaboração própria).

Quadro 2 Narrativa \#2: "Let`s move on, please."

Uma reunião individual é especialmente valorizada. Constitui um momento de aprendizagem, de concessão de atenção dedicada, é uma vantagem (potencialmente diferenciante). O conhecimento reside nos indivíduos, não tanto na organização. Aprende-se com os pares, com os líderes, em particular com aqueles reputados como conhecedores. Até deixarem de o ser, até se findar o interesse (a novidade). Várias práticas celebram o indivíduo. O nome e os números na parede, num écran, à vista de todos, instilam um sentido de competição. Há um elemento transacional, que tende a enformar, neste contexto, as relações de emprego. Menos de dez por cento da equipa tem um contrato de trabalho superior a doze meses. Novos elementos ficam seis meses, três meses, um mês, uma semana, um dia. Por opção própria, por opção da organização, de quem a gere. Que gere uma organização, uma equipa, em muitos casos, pela primeira vez. Numa start-up dão-se oportunidades. O turnover é elevado: mais de 40 saídas durante o período de observação considerado.

A colaboração. O individualismo e a colaboração. As relações, em particular, nos níveis de gestão, aparentam ser marcadas pela desconfiança. Há uma indisponibilidade individual para assumir fragilidades, vulnerabilidade. Muito ego em presença, muito "finger-pointing", uma harmonia artificial, o uso de linguagem agressiva. A colaboração é, pelos motivos indicados, um problema. A confiança é tipicamente atribuída, não emerge como construção (social). O conflito é tendencialmente evitado, negligenciado, secundarizado. Trata-se de um incidente, de uma incidência (lateral). "Let's move on, please", ouve-se numa reunião. Não se sabe, ao certo, como lidar com o conflito, com o mau exemplo, o excesso de ego tornado agressão.

"Se não for eu a fazê-lo, isso de certeza que não será bem feito", ouve-se numa reunião. Num sentido próximo, há problemas de responsabilização, de conciliação da responsabilização (por um atraso numa "entrega", um gasto inconsequente) com a incerteza sempre latente, com a intenção declarada de manutenção de um minimalismo gestionário, de fomento de uma organização adhocrática, de práticas ancoradas na autorregulação individual. Em termos gerais, as relações parecem ser marcadas por uma dimensão instrumental e uma racionalidade imediatista. Ficar na start-up enquanto se está a aprender, a ganhar, enquanto representar uma vantagem (individual). A ausência de clareza de propósito(s), a sua flutuação persistente, a dificuldade em dar uma tarefa por encerrada, parecem contribuir para um sentido de implicação frouxa com os objetivos da organização, com o seu futuro. Em particular, com os objetivos partilhados, coletivos.

Fonte: Extratos de diário de campo (Elaboração própria).

\section{Uma hipertrofia do presente: Análise e discussão de duas narrativas}

Analisando as narrativas apresentadas, importa salientar a existência de um conjunto de especificidades observáveis ao nível das relações estabelecidas com e na organização start-up considerada. No concernente à relação que os indivíduos estabelecem com a organização start-up, destacamos dois aspetos particulares: o foco colocado na ação e a impermanência normativa. Em sentido próximo, nos mesmos suportes narrativos salientam-se dois caracterizadores das relações estabelecidas na organização considerada: o fervor finito da experiência vivida e a secundarização do conflito. Trata-se de elementos que constituem implicações de uma coordenada de constrangimento institucional da ação na e da organização start-up: o foco (discursivo e praxeológico) que é colocado no momento presente, num sentido de "presente psicológico" (Miles, 1964, pp. 457-458), uma hipertrofia do presente que resulta de uma lógica de acção imediatista.

Como é ilustrado por Ries (2016), uma organização start-up deve procurar desenvolver soluções, produtos, serviços minimamente viáveis, uma lógica que constitui, em si mesmo, um desafio à lógica industrial dos zero defeitos, da qualidade total. A necessidade de agilidade (a "lean start-up") (Ries, 2016) a mudança persistente, a descontinuidade, emerge neste contexto com um efeito visado, de implicações não desprezíveis, no plano organizacional, social, individual. No caso considerado, regista-se uma tendência de imersão na tarefa, na atividade de trabalho, na resolução do problema 
presente (Saunders \& Ahuja, 2006), cuja concretização imediata é vivida com sentido de urgência. A agilidade é assimilada enquanto capacidade de agir, de fazer coisas ("getting sh!t done"), e não tanto em cuidar de fazer as coisas certas.

Um orçamento anual é concebido, validado e entregue no próprio dia. O foco é colocado no que acontece (cf. narrativa \#1). O foco na ação, no presente imediato, na urgência, figuram como paliativos da incerteza: "O que a start-up é ou faz, é no essencial incerto, flutuante, efémero" (cf. narrativa \#1). O objetivo singular, disruptivo, tipicamente complexo, é, nos termos de Lundin e Soderholm (1995), a raison d 'être, o motivo fundador de uma organização temporária. A estruturação particular, contingencial, de papéis e de responsabilidades apensos à concretização de uma tarefa, define um outro traço distintivo de uma organização temporária. Como mencionado na narrativa \#1: "(...) Não interessa tanto definir aquilo que se é, aquilo que a start-up é, aquilo que cada área ou função "é", o que é preciso é que haja coisas que aconteçam. A start-up faz, logo existe".

Por outro lado, a capacidade de mudança súbita, de introdução de descontinuidades na organização (e.g., no plano da contratação, das opções tecnológicas, dos modelos de coordenação interna de atividade), é valorizada como sintoma e possibilidade de demonstração (material e discursiva) de progresso - uma prova de existência, no plano institucional. Há mudanças, há descontinuidades que são deliberadas, visando o efeito de disrupção que se projeta na descontinuidade que é consumada: uma nova contratação, a decisão de ir para um novo país, uma mudança estrutural interna. A impermanência normativa permite, neste sentido, a afirmação cíclica de novas identidades organizacionais, de novas "caracterizações de empresa" (termo empregue por um dos responsáveis entrevistados), que contribuem para assegurar a atração e o encorajamento da identificação antecipatória com a organização (de investidores, de parceiros, de trabalhadores). Trata-se de uma prática de controlo normativo, de gestão simbólica de tipo bottom-up, característica de contextos organizacionais recém-constituídos, turbulentos, de funcionamento orgânico (Weick, 1996).

$\mathrm{Na}$ organização start-up considerada, são vários os elementos que evidenciam a difusão de uma concepção específica do tempo, de natureza linear, e não cíclica ou circular (Boutinet, 1997): "Não há tempo para pensar. Age-se. Os processos de decisão são, muitas vezes, marcados pela intempestividade, por um quórum parcial, a participação rarefeita" (cf. narrativa \#1). Trata-se de uma orientação que não favorece o desenvolvimento de um investimento, material e simbólico (dos indivíduos, das organizações), na interação social, e a longevidade das relações sociais: "A ausência de clareza de propósito(s), a sua flutuação persistente, a dificuldade em dar uma tarefa por encerrada, parecem contribuir para um sentido de implicação frouxa com os objetivos da organização, com o seu futuro" (cf. narrativa \#2).

No caso considerado, as relações sociais estabelecidas na organização são valorizadas, e são vividas com especial fervor, um fervor finito, sugerimos: "São muitas horas passadas a fazer coisas ("I 'm getting sh!t done" - ouve-se frequentemente). As pessoas faziam, de facto, coisas. Tentavam, aprendiam, experimentavam, experimentavam-se" (cf. narrativa \#1). A perceção de finitude (temporal) da integração na organização start-up aparenta introduzir especificidades nestas relações, uma circunstância que representa uma vulnerabilidade na capacidade de partilha de conhecimento, de constituição de um sentido de interdependência e de confiança, de continuidade social. Desta circunstância decorre uma atmosfera de fervor que tende a favorecer uma experiência individual intensa, de relações sociais vividas como sendo, no essencial, passageiras, "one night stands" (Meyerson, Weick \& Kramer, 1996, p. 168).

Neste contexto, observa-se que a confiança e o sentido de pertença (ao grupo, à equipa, à organização start-up) tendem a ser presumida in situ pelos indivíduos, de forma súbita, instantânea, não resultando de uma aquisição gradual, construída a partir da sedimentação continuada das relações sociais. Caracterizando-se as organizações start-up por dispositivos formais de organização menos extensos e burocráticos, observa-se que a confiança presumida, importada como crédito idiossincrático de uma trajetória individual, e a suspensão temporária da dúvida, delimitam, neste contexto, mecanismos privilegiados de regulação das interações sociais numa organização temporária. No caso considerado, presumiu-se a capacidade do investigador criar e apresentar um orçamento para a área de recursos humanos da start-up, em dois dias, que enquadrasse o crescimento esperado para o ano seguinte (cf. narrativa \#1).

A antecipação de um futuro partilhado como sendo pouco provável, tende a fazer com que numa organização start-up se desvalorize, como necessidade percebida, a regulação da coesão interna e a existência de conflitos, a análise dos conflitos registados no quotidiano de trabalho. Numa organização temporária como uma organização start-up, existem menos oportunidades para reduzir distâncias cognitivas entre indivíduos e para a sedimentação de laços sociais e emocionais: "O conflito é tendencialmente evitado, negligenciado, secundarizado. Trata-se de um incidente, de uma incidência (lateral). "Let`s move on, please", ouve-se numa reunião" (cf. narrativa \#2). Como é mencionado na narrativa \#2, da aparente dificuldade de sedimentação do sentido 
de pertença, a sua fluidez, decorre a emergência da transação como substituto da relação de emprego:

Há um elemento transacional, instrumental, que informa, neste contexto, as relações de emprego. Menos de dez por cento da equipa tem um contrato de trabalho superior a doze meses. Novos elementos ficam seis meses, três meses, um mês, uma semana, um dia. Trata-se de um fator que apresenta a organização start-up como milieu específico de ação marcado por possíveis conflitos de lealdade, por filiações múltiplas, difusas, concorrentes: Se não for eu a fazê-lo, isso de certeza que não será bem feito (cf. narrativa \#2).

\section{Conclusão}

A atividade da e na organização start-up considerada como objeto de análise no presente artigo apresenta-se constrangida pelo tempo - o tempo valorizado como recurso, como recurso técnico, finito (Boutinet, 1997). O contrato social e psicológico emergente neste contexto delimita um eixo de condicionamento normativo, oculto, omisso ou pouco invocado em termos discursivos, mas presente e atuante no plano material, como ilustrado em termos empíricos pelas narrativas apresentadas. Este é o principal contributo do estudo realizado: a ilustração, numa perspectiva vivida, da especificidade de um conjunto de atributos organizacionais e situacionais que poderão contribuir para o aprofundamento da compreensão das relações sociais, das práticas e da cultura do universo organizacional perfilhado pelo estudo, um universo em si mesmo relevante para uma putativa recomposição das práticas que enformam a actividade económica nacional.

O estudo realizado apresenta limitações. Trata-se de um estudo centrada na análise de um contexto organizacional particular, uma organização start-up em estado nascente (early stage) de desenvolvimento; a análise apresentada baseia-se em materiais empíricos de índole fundamentalmente qualitativa; a informação recolhida é apresentada de uma forma particular - uma narrativa. Em secção específica, procurámos enquadrar as opções teórico-metodológicas perfilhadas, atendendo à natureza do objeto considerado em termos analíticos. Importará confrontar a análise e as direções de interpretação sugeridas, realizando estudos de caso múltiplo, que articulem diferentes técnicas de recolha de materiais empíricos (e.g., entrevista, questionário, diário individual de incidentes, shadowing), que tomem como referente organizações start-up que apresentem maior dimensão e maturidade organizacional (e.g., scale-ups).

A impermanência normativa, o foco colocado na ação, a secundarização do conflito, o fervor finito da experiência vivida, constituem descritores de situações concretas de trabalho e de emprego, que permitem alargar os quadros de compreensão do funcionamento de uma organização start-up, de explicação do seu sucesso, do seu (elevado) fracasso. A análise das condições de interação, e das situações de trabalho numa organização start-up afigura-se, a este nível, um campo de pesquisa especialmente profícuo. Trata-se de uma direção de pesquisa relevante, no sentido de aprofundar o conhecimento existente sobre os modos de funcionamento de uma organização start-up em Portugal, equacionando os modos de inscrição das suas práticas, no contexto da emergência de um ecossistema nacional de gestão da inovação, da transferência de tecnologia, de empreendedorismo.

\section{Referências biliográficas}

Aldrich, H. E., \& Martinez, M. A. (2001). Many are called, but few are chosen: An evolutionary perspective for the study of entrepreneurship. Entrepreneurship: Theory and Practice, 25(3), 41-56.

Bakker, R. (2010). Taking stock of temporary organizational forms: A systematic review and research agenda. International Journal of Management Reviews, 12(4), 466-486.

Baptista, R., \& Preto, M. (2011). New firm formation and employment growth: Regional and business dynamics. Small Business Economics, 36(4), 419-442.

Blank, S. (2010, 25 de Janeiro). What's a start-up? First principles [Blogue]. Disponível em https:// steveblank.com/2010/01/25/whats-a-startup-first-principles/

Boutinet, J. (1997 [1990]). Antropologia do projecto. Lisboa: Instituto Piaget.

Butcher, M. (2017, 14 de Fevereiro). In 2016 Lisbon fired-up its startup engines: 2017 will hear them roar. Techcrunch. Disponível em https://techcrunch.com/2017/02/14/in-2016-lisbon-fired-up-its-startup-engines-2017-will-hear-them-roar/

CB INSIGHTS (2016, 12 de Setembro). Start-up continent: The most well-funded tech start-ups in Europe. Disponível em https://www.cbinsights. com/research/top-startups-europe-map/

Cole, C. (2013). Stories from the lived and living fieldwork process. Qualitative Research in Organizations and Management: An International Journal, $8(1), 50-69$.

Cunliffe, A. L., \& Karunanayake, G. (2013). Working within hyphen-spaces in ethnographic research: Implications for research identities and practice. Organizational Research Methods, 16(3), 364-392.

Czarniawska, B. (1997). Narrating the organization: Dramas of institutional identity. Chicago: The University of Chicago Press.

Czarniawska, B. (2007). Shadowing: And other techniques of doing fieldwork in modern so- 
cieties. Copenhagen: Copenhagen Business School Press.

Eriksen, T. (2001). Tyranny of the moment. London: Pluto Press.

Flyvberg, B. (2006). Five misunderstandings about case-study research. Qualitative Inquiry, 12(2), 219-245.

Graham, P. (2012). Start-up=Growth [Blogue]. Disponível em http://www.paulgraham.com/growth.html

Hanage, R., Scott, J. M., \& Davies, M. A. P. (2015). From great expectations to hard times: A longitudinal study of creative graduate new ventures. International Journal of Entrepreneurial Behavior and Research, 22(1), 17-38.

Hwang, V., \& Horowitt, G. (2012). The rainforest - The secret to build the next Silicon Valley. New York: Regenwald Publishers.

Johnson, P., \& Duberley, J. (2003). Reflexivity in management research. Journal of Management Studies, 40(5), 1279-1303.

Krauss, G. (2009). Les jeunes entreprises pionnières face à l'incertitude: La construction sociale de l'échec. Revue Française de Socio-Économie, (3), 169-186.

Kriss, S. (2016, 11 de Novembro). Watching the world rot at Europe's largest tech conference, Atlantic. Disponível em: https://www.theatlantic.com/ technology/archive/2016/11/the-warped-world-of-web-summit/508442/

Lundin, R., \& Soderholm, A. (1995). A theory of the temporary organization. Scandinavian Journal of Management, 11(4), 437-455.

McLaughlin, P., Bessant, J., \& Smart, P. (2005). Developing an organizational culture that facilitates radical innovation in a mature small to medium sized company: Emergent findings (Working paper). Cranfield University. Disponível em https:// dspace.lib.cranfield.ac.uk/bitstream/1826/858/2/ SWP0405.pdf

Medeiros, J. (2016, 5 de Setembro). Europe's hottest start-ups 2016: Lisbon. Wired. Disponível em http://www. wired.co.uk/article/european-start-ups-2016-lisbon

Meyerson, D., Weick, K. E., \& Kramer, R. M. (1996). Swift trust and temporary groups. In R. Kramer, \& R. Tyler (Eds.), Trust in organizations: Frontiers of theory and research (pp. 166-195). Thousand Oaks, CA: Sage.

Miles, M. (Ed.) (1964). On temporary systems. In Innovation in education (pp. 437-490). New York: Teachers College Press.

Oliveira, C. (2016, 27 de Fevereiro). A caminho de Startup Nation. Dinheiro Vivo. Disponível em https://www.dinheirovivo.pt/opiniao/a-caminho-de-startup-nation

Ragin, C., \& Amoroso, L. (2011). Constructing social research: The unity and diversity of method. New York: Sage.

Ramos, J. (2017, 2 de Abril). Quatro unicórnios e 835 contratações. Expresso. Disponível em http:// expresso.sapo.pt/economia/2017-04-02-Quatro-unicornios-e-835-contratacoes

Ries, E. (2016 [2011]). Lean start-up. Lisboa: Prime Books.

Robinson, E. (2017, 31 de Fevereiro). Portugal once launched ships, now it launches startups, Bloomberg. Disponível em https://www.bloomberg. $\mathrm{com} /$ news/articles/2017-02-01/portugal-once-launched-ships-now-it-launches-startups

Rocha, A., Simões, V. C., Mello, R. C. de, \& Carneiro, J. (2017). From global start-ups to the borderless firm: Why and how to build a worldwide value system. Journal of International Entrepreneurship, 15(2), 121-144.

Santos, N. (2016, 24 de Setembro). A oportunidade de sermos um outro país. Expresso. Disponível em http://expresso.sapo.pt/opiniao/opiniao_ cem por cento/2016-09-23-A-oportunidade-de-sermos-outro-pais

Saunders, C., \& Ahuja, M. (2006). Are all distributed teams the same? Differentiating between temporary and ongoing distributed teams. Small Group Research, 37(6), 662-700.

Singh, S., Corner, P. D., \& Pavlovich, K. (2015). Failed, not finished: A narrative approach to understanding venture failure stigmatization. Journal of Business Venturing, 30(1), 150-166.

Start-up Europe Partnership. (2015). Portugal rising: Mapping ICT scaleups (Relatório No 10). Belgium: SEP Monitor.

Startup Genome. (2017). Startup genome ecosystem: Report 2017. San Francisco: Startup Genome LLC.

Ucbasaran, D., Shepherd, D. A., Lockett, A., \& Lyon, S. J. (2013). Life after business failure: The process and consequences of business failure for entrepreneurs. Journal of Business Management, $39(1), 163-202$.

Urze, P., \& Abreu, A. (2015). Innovation from academiaindustry symbiosis. In L. M. Camarinha-Matos, F. Bénaben, \& W. Picard (Eds.), Risks and resilience of collaborative networks (pp. 337-344). Berlin: Springer.

Weick, K. (1996). Sensemaking in organizations. Thousand Oaks, CA: Sage.

Recebido a 22/09/2017. Aceite para publicação a 07/11/2017.

João Vasco Coelho (vasco.jcoelho@gmail.com). Centro de Investigação e Estudos em Sociologia (CIES-IUL), Instituto Universitário de Lisboa (ISCTE-IUL). Edifício ISCTE, Av. das Forças Armadas, 1649-026 Lisboa, Portugal. 